\title{
Useful Argumentation: A Critique of the Epistemological Approach
}

\section{BRIAN HuSS}

\author{
York University
}

\begin{abstract}
The main rationale for adopting the epistemological approach to argumentation seems to take the form of a criticism of the consensus theory. This criticism says that some instances of clearly bad argumentation count as acceptable instances of argumentation on the consensus theory. Supposedly, the epistemological approach does not have this problem. I suggest that the kind of normativity argumentation theorists should be concerned with is the normativity associated with giving real-world advice on how to partake in a critical discussion. I try to show that when we understand the normativity of argumentative standards in this way, the main criticism of the consensus theory falls short, and the epistemological approach does not really have the advantages over the consensus theory that it is purported to have. If I am right, then the main reason offered for adopting the epistemological approach fails, and we should stick with the consensus theory.
\end{abstract}

\begin{abstract}
Résumé: La raison principale pour appliquer l'approche épistémologique à l'argumentation semble être une critique contre la théorie du consensus : il y a des argumentations évidemment mauvaises qui sont acceptables selon la théorie du consensus, mais apparemment l'approche épistémologique n'a pas ce problème. Je suggère que les théoriciens de l'argumentation devraient s'intéresser à la normativité associée avec des conseils pratiques sur la participation aux discussions critiques. J'essaie de montrer que lorsqu'on saisit les règles argumentatives de cette façon, l'objection principale contre la théorie du consensus échoue, et que l'approche épistémologique n'a donc pas les avantages sur la théorie du consensus qu'elle prétend avoir. Si j'ai raison, nous devrions adopter la théorie du consensus au lieu de l'approche épistémologique.
\end{abstract}

Keywords: epistemological approach, consensus theory, dispute resolution theory, question-begging, rationality, normativity, pragmatism, deep disagreements, universal audience

\section{Introduction}

Very generally, the epistemological approach to argumentation holds that proper argumentation produces knowledge or epistemically justified belief for those who partake in the argument. Some have argued that it is superior to consensus theory, according to which proper argumentation results in consensus between participants. I hope to show that if we are concerned primarily with developing a normative theory of argumentation that yields real-world advice that people can actually use 
when engaging in argument, then the epistemological approach is inferior to the consensus approach. Or, at the very least, if we want to have a theory of argumentation that yields useful advice, then the epistemological approach does not really have the advantages over the consensus theory that it is purported to have. In other words, when we understand the normativity of argumentative standards in the right way, there is no reason to turn to the epistemological approach.

In what follows, I will take John Biro and Harvey Siegel's view, as well as Alvin Goldman's view, as representative of the epistemological approach (Biro \& Siegel 1992, 1997; Goldman 1999).' I will take Frans van Eemeren and Rob Grootendorst's view as representative of the consensus theory, though I think their theory may need at least one important modification (van Eemeren \& Grootendorst 1992, 2003a, 2003b). I will begin by saying something about the consensus theory I endorse. I will then present a standard objection to the consensus theory, an objection which is supposed to serve as the main rationale for adopting the epistemological approach. Finally, I will try to answer this objection and hence show that the main rationale for the epistemological approach fails. In so doing, I hope to shed some light on the kind of normativity that we should be concerned with when it comes to argumentation. I should stress that my main goal is not to defend the consensus theory against all possible objections, but rather to focus on what seems to be the primary rationale offered for preferring the epistemological approach. I want to show that this rationale does not warrant a rejection of the consensus theory and hence that the most common reason for adopting the epistemological approach fails.

\section{The Consensus Theory}

I prefer to speak of consensus theory, rather than dispute-resolution theory, because the view I want to defend against the epistemological approach can be applied to monological argumentation as well as dialogical argumentation. Since there need not be any dispute in monological argumentation, it is better to think in terms of consensus. It should also be noted that consensus theory is importantly different from the pure persuasion view of argumentation. In order for all parties to an argument to reach consensus, they must truly believe whatever they agree to, whereas a persuader need not believe what she persuades you of.

For the most part, the view I wish to defend is the same as van Eemeren and Grootendorst's pragma-dialectical procedure for adjudicating a critical discussion. This procedure involves several rules, but for present purposes it is enough to focus on just two sub-procedures: what they call the intersubjective identification procedure and the intersubjective inference procedure (2003a). The intersubjective identification procedure is used in dialogical argumentation to determine which propositions may be used as premises over the course of the discussion. These propositions may include values or supposed facts. As the name suggests, those propositions that are acceptable are those that are intersubjective, i.e., those that all 
parties to the discussion believe to begin with. Anything in the set of jointly-accepted propositions may be used by any participant as premises in an argument, and anything outside that set may not be used. (For monological argumentation, the corresponding requirement would say that the arguer may use premises that both she and her audience believe, and may not use premises that either she or the audience does not accept.)

The intersubjective inference procedure is used to determine what kinds of inferences are acceptable over the course of the discussion. Those inferences or inference types that are deemed acceptable by all parties may be used by any participant in presenting an argument. Those inferences or inference types that are not initially agreed upon by all parties may not be used. (Again, there is a corresponding requirement for monological argumentation.)

These standards of argumentation are internal standards. They are internal to the discussion in that they depend only on the thoughts of those who partake in the discussion. They are different from external standards, which tell us that particular propositions or inferences are either acceptable or unacceptable, regardless of what the participants think. This is the main point of difference between consensus theory and the epistemological approach. The epistemological approach insists on external standards, which are themselves subject to the standards of knowledge or epistemic justification. As we will soon see, this insistence on external standards is the main reason why the epistemological approach fails to offer useful advice to those engaged in argument.

But there is at least one point where van Eemeren and Grootendorst can be interpreted as giving up a purely internal conception of argumentation standards. They say, "An ideal model aims at providing an adequate grasp of argumentative discourse by specifying which modes of arguing are acceptable to a rational judge in view of a certain philosophical conception of reasonableness" (1992, 7, emphasis added). Biro and Siegel, quoting the same passage, point out that the italicized portion amounts to an abandonment of what is unique about van Eemeren and Grootendorst's view (Biro \& Siegel 1997, 283). For if they allow for a rational judge who is bound by a certain conception of reasonableness to determine which modes of arguing are acceptable and which aren't, then they seem to be left with an epistemological view of good argumentation. Presumably, the imaginary rational judge mentioned here is committed to epistemic justification, regardless of what the actual participants to the discussion think. If so, then we are left with an external standard of the kind advocated by the epistemological approach.

I believe Biro and Siegel's complaint reveals a serious problem with van Eeemeren and Grootendorst's view, or at least with their presentation of it. Once the rational judge is introduced, it is difficult to see what is unique about the consensus theory. Van Eemeren and Grootendorst should not allow for the rational judge. They should stick with the intersubjective identification procedure and the intersubjective inference procedure as the main components of their theory. 
Biro and Siegel claim that van Eemeren and Grootendorst are left with a dilemma: "... either their account is at bottom a descriptivist or rhetorical one which fails to account for the normativity of judgments concerning arguments, or it does account for that normativity, in which case it is in fact an epistemic account of the sort we have been advocating" (1997, 283). My view is that this dilemma is a false dichotomy. It is possible to opt for the "rhetorical" account and at the same time capture a high degree of normativity, despite Biro and Siegel's claims to the contrary. Furthermore, this normativity is the right kind of normativity. The normativity associated with the epistemological approach, on the other hand, is not of the right kind, if we want an account of good argumentation that is at all useful to real people living in the real world. I will now try to prove this claim by considering the main objection offered against the consensus theory.

\section{The Rationale for the Epistemological Approach}

As mentioned earlier, it seems the main rationale for adopting the epistemological approach takes the form of a criticism of the consensus theory. This criticism focuses on the kinds of standards yielded by the intersubjective identification procedure and the intersubjective inference procedure. The claim is that in some cases these procedures will yield standards that are clearly not good standards of argumentation. For example, Biro and Siegel, as well as Goldman, point out that if two people are engaged in argument and both accept the gambler's fallacy, then when we apply the intersubjective inference procedure, we will get the unintuitive result that the gambler's fallacy is appropriate for that particular discussion. Surely it's not, the argument goes, and hence so much the worse for the intersubjective inference procedure and the consensus theory. After all, the gambler's fallacy is a fallacy, but the consensus theory cannot account for this fact in all cases. Similar considerations lead advocates of the epistemological approach to reject the intersubjective identification procedure. Since it too relies on shared beliefs, and since shared beliefs can be unjustified, false, or downright crazy, it follows that the procedure does not yield the right kinds of standards for good argumentation.

Note that when we say a move in an argument is fallacious we are making a hopelessly normative claim. We say that the move is irrational or in some other way not the right kind of move to make. The advocates of the epistemological approach understand this very well. Biro and Siegel tell us, "What is needed is a property such that while it is itself unproblematically descriptive, in explaining the concept of a fallacy it explains, at the same time, its normative dimension. We propose that an epistemic conception of fallacy focuses on just such a property" $(1992,92)$. The supposed problem with the consensus theory is that in some cases, e.g., when all participants to a discussion accept the gambler's fallacy as a valid inference, there is a normative judgment that should be made but which cannot be accommodated by the consensus theory. The reason is that the consensus theory relies on a set of internal standards. In order to get the right kind of 
normativity, according to the advocates of the epistemological approach, we must use an external standard. And the external standard that seems best suited to the task is the standard of epistemic justification or knowledge. The gambler's fallacy is a fallacy, even if all participants to a discussion fail to realize it, because one is not epistemically justified in thinking that the last ten rolls of the dice have anything to do with the next roll. If you like reliabalism with respect to justification, you might say that making use of the gambler's fallacy is an unreliable belief-forming process. And however you understand justification, a belief based on the gambler's fallacy cannot constitute knowledge. Since what we're after in argumentation is justified belief or knowledge, we must use an external standard, according to the advocates of the epistemological approach.

\section{Reply: The Right Kind of Normativity-Giving Advice}

There is something to be said for the epistemological approach, I think, if our only concern is to make after-the-fact evaluations about pieces of argumentation. If all we are concerned to do is pass judgment on this or that argumentative move long after it is made, then the epistemological approach works fairly well. But if we want to be able to tell people how they ought to go about holding a critical discussion, the epistemological approach works less well. Furthermore, it is this advice-giving kind of normativity that argumentation theorists should be interested in. Or, at least, it is one of the aspects of argumentation that they should be interested in. So if the epistemological approach doesn't yield useful, real-world advice about how to go about arguing; it neglects a big part-the most important part, I think-of a good theory of argumentation.

To see the problem, we can consider the advice yielded by the epistemological approach for those who partake in critical discussion. The advice seems to look something like this: "Make sure that all of the propositions you use are epistemically justified and make sure that all of your inferences are (roughly) truth-preserving." The problem with this piece of advice is that if each of the participants to a critical discussion honestly believes everything they say and honestly believes that all of their inferences are valid (in the broad sense), then they will act in accordance with this advice, regardless of whether it is offered. They won't follow the advice, however, because to follow a piece of advice is to make sure that you do things you might not ordinarily do or to make sure that you don't do things that you might otherwise be tempted to do. If, on the other hand, the participants to a critical discussion do not honestly believe everything they say or do not honestly believe that their inferences work, then they are not honest participants. And when the participants are not honest, it's hard to see how they can be said to be engaged in critical discussion in the first place. In other words, honest discourse in which all of the participants believe that everything they say is true and epistemically justified is constitutive of critical discussion. The epistemological approach and the consensus theory seem to agree on this point. (The pure persuasion view, on 
the other hand, seems to entail the denial of this claim, which demonstrates (a) why the pure persuasion view is importantly different from the consensus theory ard (b) why the pure persuasion view is mistaken.) At any rate, the epistemological approach can't have an advantage over the consensus theory in cases of dishonest discussion, because the consensus theory yields the right result: Participants ought to believe everything they say (because you and I can't reach consensus on a claim that you don't believe).

The key point here is that there is all the difference in the world between acting in accordance with advice and acting on the basis of advice. (Think of Kant's distinction between acting in accordance with duty and acting out of duty.) Useful advice is advice you might act on the basis of-advice you might actually follownot advice that you will act in accordance with, come what may. When the participants to a critical discussion are honest, they will always act in accordance with the advice yielded by the epistemological account, but they will not follow it. Therefore, the advice yielded by the epistemological account is not useful advice.

When every party to a discussion accepts the gambler's fallacy, they think the inference from the results of the last ten rolls of the dice to the result of the next roll is an inference that is likely to result in true or epistemically justified beliefs. Furthermore, this is true regardless of whether, before-hand, an advocate of the epistemological approach told them to make sure their inferences are good inferences. This is evidence for the claim that the advice yielded by the epistemological approach is not the kind of advice that anyone might follow. But suppose the advocate of the epistemological approach, who also thinks the inference associated with the gambler's fallacy is a bad inference, enters the discussion halfway through. Well, then, she is now a participant to the discussion, and the consensus theory yields this advice: Do not make use of an inference that even one participant rejects. Now the original participants can either follow the advice offered or not. If they do, they're arguing well, and if they don't they're arguing poorly. They are tempted by the gambler's fallacy, but one of the participants rejects it. So, they can either follow the advice and stop using the inference or they can choose not to follow the advice and ignore the newcomer's complaints. This is enough to show that the consensus theory, unlike the epistemological approach, yields followable advice. And, again, the only useful advice is followable advice.

At this point, one might object that my characterization of the advice yielded by the epistemological approach is unfair. Perhaps the advice is not just that you should make use of propositions that are epistemically justified and inferences that are truth-preserving. Since we have at least some idea of what kinds of propositions are epistemically justified and what kinds of inferences are truth-preserving, we can say more. We might give the participants a list of fallacies to avoid, for example. Now when the participants are tempted by the gambler's fallacy, they can see that it is included in the list of fallacies and either follow our advice or not. Isn't this enough to show that the epistemological approach can yield useful advice? 
The problem now, though, is that although such advice is indeed followable, it still might not be useful advice. It is a necessary condition of useful advice that it be followable, but not a sufficient condition. Useful advice must also have something in the way of motivational force. Or, if you prefer, there is absolutely no reason to offer advice that is sure to lack any motivational force. This creates a dilemma for the advocate of the epistemological view: either the advice she gives fails to motivate, or it motivates but is no different from the advice yielded by the consensus theory. If the first horn of the dilemma is right, then the epistemological approach still fails to capture the right kind of normativity. If the second horn is accepted, then the main rationale for rejecting the consensus theory and adopting the epistemological approach disappears.

In order to see the dilemma, consider again a group of gamblers engaged in critical discussion. Suppose we've told them that the gambler's fallacy amounts to a bad inference, and we have suggested that they not make use of it. Suppose too that our gamblers are honest participants who want to find out the truth. What happens if they fail to see why the gambler's fallacy is a fallacy? That is, what happens if they don't understand why the inference is a bad inference? The answer is that the advice on offer will fail to motivate them in any way. If they continue to think the inference is likely to yield epistemically justified beliefs, they will continue to use it. Of course the advocate of the epistemological approach will deem their discussion a bad discussion, but an after-the-fact judgment about the quality of the discussion and a piece of advice that motivates people to discuss issues in a particular way are two very different things. Insofar as we are interested in a theory of argumentation that yields real-world advice, the after-the-fact judgment yielded by the epistemological approach won't interest us.

If, on the other hand, the gamblers see why the gambler's fallacy doesn't work as a truth-preserving inference, then they might be motivated to avoid it, but this motivation is captured very well by the consensus theory. What motivates them to avoid the gambler's fallacy is that they come together as truth-seeking rational agents and agree that the inference is not likely to yield epistemically justified beliefs. It is this agreement- the agreement required by the intersubjective inference procedure-that motivates them to both avoid the gambler's fallacy and continue with the discussion. For suppose that there is one holdout in our group of gamblers. That is, suppose every gambler sees the invalidity of the gambler's fallacy except one; she continues to think the inference results in epistemically justified beliefs. It is now very difficult to see why the other gamblers would be at all inclined to both (a) avoid the fallacy in their discussion and (b) continue to talk to the holdout. They may be motivated to convince her that the gambler's fallacy is a fallacy by making use of propositions she already believes and inferences she already thinks are valid, but in that case they would be doing exactly what the consensus theory directs them to do. Or, they may be motivated to exclude her from the discussion, but then neither the epistemological approach nor the consensus theory can have anything to say about the situation, since both views are theories about critical 
discussions, not theories about who we should agree to talk to or refuse to talk to. If the other gamblers agree to avoid the gambler's fallacy and exclude the holdout, then they are acting in such a way that is compatible with both the epistemological approach and the consensus theory.

At this point the advocate of the epistemological approach might object by claiming that the other gamblers ought to exclude the holdout. Since she accepts something that is not epistemically acceptable, she ought not be allowed to participate. But insofar as the epistemological approach yields this result, so does the consensus theory. If the discussion is centred on the probability associated with the next throw of the dice, and if the holdout doesn't accept a basic tenet of probability theory that the others do accept, then there is no way to reach consensus, and hence no point in taiking to the holdout. Insofar as the epistemological approach yields the result that the other gamblers should try to convince the holdout that the gambler's fallacy is a bad inference, so does the consensus theory. For then the issue under discussion is not the result of the next throw of the dice, but rather the correct view of probability theory. If that is the issue, then the other gamblers must try to convince the holdout using propositions and inferences she already accepts. Otherwise, a critical discussion about probability theory that involves the holdout is utterly pointless.

\section{The Prohibition on Antagonistic Question Begging}

Again, what emerges from a comparison of the epistemological approach and the consensus theory is that the epistemological approach makes use of external standards for good argumentation, whereas the consensus theory makes use of internal standards only. At the heart of the consensus theory is a prohibition on what might be called antagonistic question begging. There are, I think, two kinds of question begging. The first is the familiar, textbook version of question begging, where an arguer assumes in the premises of an argument the truth of the conclusion. This kind of question begging is often referred to as circular reasoning. Circular reasoning can be a feature of arguments themselves as well as argumentation, and hence is not sensitive to context. The premises of an argument either assume the truth of the conclusion or they don't, regardless of the circumstances in which the argument is offered. There is much to be said about the relative merits of the consensus theory and the epistemological approach when it comes to capturing the wrongness of circular reasoning. I will not discuss this issue here.

The kind of question begging that is important for present purposes is antagonistic question begging. (The intersubjective identification procedure and the intersubjective inference procedure of van Eemeren and Grootendorst's account amount to a prohibition on antagonistic question begging.) Antagonistic question begging is sensitive to context, and cannot be a property of arguments themselves. It can only be a property of particular instances of argumentation. To engage in antagonistic question begging is to beg the question against another discussant. In other words, 
antagonistic question begging is committed in dialogical argumentation when a discussant merely assumes something that her opponent denies. I say "merely assumes" to indicate that the discussant who antagonistically question begs does not offer an argument in support of whatever her co-discussants deny. The discussant who antagonistically question begs, just "helps herself" to a premise that her co-discussants deny from the very start. For example, the abortion debate in North America often degenerates into a shouting match because each side tends to engage in antagonistic question begging against the other. Pro-life advocates often just help themselves to the claim that a fetus is a person, even though their opponents deny this claim from the start, and pro-choice advocates often just help themselves to the claim that a woman can do whatever she wants with her own body, even though their opponents deny this claim from the start. At the core of the consensus theory is the view that there is absolutely no point in entering into a critical discussion in the first place if any of the participants are intent on engaging in antagonistic question begging. It is for this reason that antagonistic question begging is forbidden. The normativity associated with the prohibition on antagonistic question begging is constitutive of a critical discussion; participants are not even having a critical discussion if they engage in antagonistic question begging, even if think that they are. So the advice offered by the consensus theory cuts right to the heart of the issue. This advice must be followed, even if one is tempted to help oneself to assumptions that one's opponent simply denies.

Due to its emphasis on external standards, it is not clear that the epistemological approach can fully account for the need to avoid antagonistic question begging in critical discussion. For suppose again that in a critical discussion there is a holdout with respect to some proposition or inference. Further suppose that all of the other discussants continue to make use of the proposition in their arguments and that the proposition is true, very well epistemically justified, and that belief in it constitutes knowledge. Then, it seems, the advocate of the epistemological approach is committed to saying that those discussants who make use of the proposition are arguing well and that the holdout is arguing poorly. The problem is that the epistemological approach seems to have nothing more to say about the case. Since the non-holdouts are epistemically justified in what they say, and the holdout isn't, the former are going about things the right way, and the latter is not. But surely it is correct that if the non-holdouts continue to discuss with the holdout, they ought to try to change her mind about the proposition in question. How, then, can the epistemological approach account for this fact? If the non-holdouts do not want to continue the discussion with the holdout as a participant, that is of course fine, but again, theories of argumentation are not usually thought to be theories of who we ought to talk to, and even if they were, it is unclear that the epistemological approach would enjoy any advantages over the consensus theory on this score.

To see why the prohibition on antagonistic question begging is so important, we might imagine cases of "ultra-deep" disagreement, where the disagreement is about some very basic standard of reasoning. ${ }^{3}$ So, for example, suppose that we 
have two discussants - a traditional logician and a dialethist. Since dialethism is the view that at least some contradictions are true, the dialethist and the traditional logician disagree about a very basic standard of reasoning. ${ }^{4}$ The critical issue is this: Should the traditional logician be allowed to just assume that no contradictions are true in her discussion with the dialethist? For anyone who thinks that we must answer this question negatively, the consensus theory should be very appealing. The epistemological approach, insofar as it retains what makes it distinct from the consensus theory, seems to yield the result that either the traditional logician or the dialethist has the rational view (where rationality is defined by external standards, e.g., the truth of the matter), and that whoever has the rational view is arguing well; the other discussant is arguing poorly. But since what counts as rational is the very issue in question in a discussion on dialethism, this seems a somewhat odd and terribly unhelpful verdict. It's not even clear that the epistemological approach can deliver a verdict about such a discussion after the fact, unless it is somehow made very clear to us over the course of the discussion that either the traditional logician or the dialethist has a view that is obviously irrational.

Still, perhaps my focus on internal standards is misguided. An anonymous referee suggests that a correct characterization of what the practice of argumentation is must have priority over internal standards of the practice. And some might think that of course we must understand what a practice consists of before we are able to determine the right way to go about it. So maybe I have got things the wrong way around. Maybe we should focus on the external standards, as the epistemological approach does. Once we have figured out what the external standards are, we can then turn to the internal standards, since the former will inform the latter.

This objection raises important issues about the very nature of philosophical investigation, and I do not have the space here to consider them fully. Suffice it to say, however, that in a great many cases a practice is best explained by offering advice on how to do it. Suppose, for example, that you know next to nothing about Canadian football. You know that it's a game Canadians play, but that is all. Now, if you ask me what Canadian football is, then my best strategy is to explain to you how people play it. Instead of trying to offer necessary and sufficient conditions for what counts as a game of Canadian football, I should instead tell you what the aim is (i.e., to score more points than your opponent) and the methods used to achieve that aim (e.g., kick the oblong ball through the uprights). That is, I should tell you what the rules of the game are. Once you know the rules, you know how the game is played. And once you know how the game is played you know what the game is. It would be very odd indeed for you to say that you know how Canadian football is played but that you do not know what it is. To my ears, at least, it sounds just as odd to say that you know how to engage in good argumentation, but that you do not know what good argumentation is. Once you know the aim of argumentation (i.e., consensus) and the methods used to achieve that aim (e.g., present arguments that don't make use of unargued-for assumptions 
your co-discussants deny), you know how to engage in good argumentation, and you thereby know what good argumentation is. If the consensus theory offers the correct advice, then it is correct not only about how you should achieve your goal, but also what your goal should be in the first place. It is impossible, it seems, in either the football case or the argumentation case to explain how to do the activity in question correctly without also specifying (at least indirectly) what the goal of the activity is. There is no way to separate the goal of a critical discussion form the advice offered for the conduct of the discussion, because the correct advice is determined by the goal.

If the consensus theory offers the correct advice, it thereby tells you what good argumentation is. And for reasons already cited, the consensus theory does a better job than the epistemological approach when it comes to telling you what goal you should have. Discussants will act in accord with the goal suggested by the epistemological approach, but they will do so just in virtue of being participants to a critical discussion. The will not act on the basis of the goal suggested by the epistemological approach.

\section{The Problem of the Universal Audience}

The insistence of the epistemological approach on external standards poses a problem that is separate but closely related to the problem it faces with respect to antagonistic question begging. If there are external standards for good argumentation, then presumably there is only one set of such standards. For if the set of standards for rationality or epistemic justification or knowledge could change depending on context, then it seems those standards wouldn't really be external standards at all; they would be standards whose correctness depends on the positions staked out and the inferences accepted by the participants to a particular discussion. If so, then we are left with a view that looks suspiciously like consensus theory, the core of which is the intersubjective identification and inference procedures.

The problem is that if there is only one set of standards that are supposed to apply to all cases of argumentation, then we get the rather colinterintuitive result that nearly all cases of critical discussion involve bad arguments. The reason is that the epistemic justification associated with nearly any claim can be called into question. To see how, consider the debate in epistemology about contextualism with respect to knowledge or justification. Suppose that two discussants in a "normal" context are in disagreement over the whereabouts of their car in a big parking lot. They take a lot of things for granted in their ensuing discussion. They assume, for example, that their senses are not deceiving them, that material objects don't just pop in and out of existence, that the universe didn't come into existence, fully-formed, five seconds ago, that they are not merely brains in vats, etc.. Furthermore, these assumptions don't seem to have any adverse effect on their discussion. It is wise for the discussants to make use of these assuinptions. But in a "non-normal" context, such as an introductory philosophy class on skepticism, 
these assumptions count as epistemically unjustified. So, then, what should we say of the pair arguing about the location of their car? It's here that the epistemological approach might be committed to the view that the discussants are both arguing badly, since they are making use of epistemically unjustified assumptions. This, however, seems to be the wrong verdict. Moreover, the claim that discussants should make use only of assumptions that are epistemically justified, as the philosopher understands justification, is terrible advice. For very few good critical discussions are possible in the first place if all discussions must adhere to the very strict standards of epistemic justification as understood by a philosopher. Note that the consensus theory seems to yield the right verdict and the right advice in this case. If both discussants deny various skeptical hypotheses in arguing about the location of their car, then (by the intersubjective identification procedure), they should indeed proceed by assuming that those hypotheses are false. If they find their car, and then wish to have a debate over the merits of radical skepticism on the way home, they ought not assume the skeptical hypotheses are false in that case. This seems to be just the right kind of advice, and it is yielded by the consensus theory, not by the epistemological approach.

Another way to phrase this criticism of the epistemological approach is to say that when we engage in argumentation, we are not always concerned with the approval of the "universal audience" (Perelman \& Olbrechts-Tyteca, 1969). We simply aren't interested, in most cases, of presenting our views in such a way that all thinking things might come to accept them. We aren't even interested, in most cases, in presenting our views in such a way that all rational thinking things might come to accept them. We want only to convince the people we are talking to. The consensus theory, with its emphasis on internal standards, is very good at accommodating this fact. The epistemological approach, with its focus on external standards, is not.

Still, perhaps I have been too quick in my criticism of the epistemological approach. At this point the advocate of that approach is likely to point out that the debate about contextualism in epistemology is a debate about what counts as knowledge or epistemic justification in the first place. The contextualist says that knowledge or justification is itself sensitive to context. So can't the advocate of the epistemological approach hold onto her claim that good argumentation is determined by epistemic standards, adopt contextualism, and thereby avoid the problem of the universal audience?

This strategy may sound appealing, but it gives up too much of what makes the epistemological approach distinct. For it is hard to see what can make the epistemic standards sensitive to context other than the unargued-for assumptions made by the parties to a discussion. If what counts as knowledge or justification in a discussion is determined by the context of that discussion, then surely the relevant aspect of the context is what the discussants think. It can't be merely the location of the discussion or the time of day that matters (though those kinds of factors might be relevant insofar as they can affect how the discussants think about the 
issue at hand). Once the advocate of the epistemological approach allows for context sensitivity, she opens the door to the consensus theory. If you insist that we must continue to talk about justification in argumentation, that is of course fine, but just notice that the kind of justification we are left with is justificationgiven-that. Some moves in an argument will be justified given that the participants accept a certain proposition and a certain kind of inference. Other moves will be unjustified given that at least one of the participants does not accept a certain proposition or a certain kind of inference. And now we have a view that looks a lot like the consensus theory. Therefore, insofar as the epistemological approach denies that there is a universal audience, it loses its uniqueness vis a vis the consensus theory. Insofar as it retains its uniqueness, it assumes a universal audience and hence doesn't yield very good advice.

\section{Arguing With Crazy People}

At a couple of points I have suggested that a theory of argumentation is not a theory about who we ought to talk to or who we ought not talk to. My claim is only that if we decide to talk to someone, then the advice yielded by the consensus theory is the correct advice for the ensuing discussion. Some may be uncomfortable with the result that discussions are not misguided or irrational, as long as they abide by the standards yielded by the consensus theory. It is this discomfort, I think, that makes the epistemological approach attractive to many. For example, Biro and Siegel complain, and Goldman echoes, that we might have discussants who agree that "whoever argues the loudest has the best argument" (Goldman 1999, 159). Surely we want to be able to say that such an argument is a horrible one. Since the consensus theory is incapable of yielding this verdict, isn't there something wrong with it?

The first thing to notice about the shouting-match example is that it is pure fantasy. It is difficult to imagine a real-world case where people really want to have a critical discussion and also agree upon volume as the only criterion for deciding whose view is correct. In the real world, people might want to engage in a literal shouting match, just for fun, but then they don't have the goal of entering into critical discussion in the first place. Of course, I understand that the example is meant to be a thought experiment-a purely imaginary case that is supposed to serve as a counterexample to the consensus view. The point, though, is that once we look for epistemically bad standards that real people might actually use, e.g., the gambler's fallacy, the impetus to deem the entire conversation irrational or misguided might be diminished somewhat.

Second, and more importantly, even if our temptation to dismiss a discussion in which the gambler's fallacy is assumed is very strong, this temptation has nothing to do with the advice that we might offer the discussants. Our temptation to dismiss the discussion comes from our understanding that the gambler's fallacy is a bad inference and the value that we place on truth and good inferences. But unless we can partake in the discussion, and show the gamblers the error of their 
ways, it's unclear that our verdict is at all useful. In other words, it's unclear that our judgment on the discussion does any good. What might do some good is useful advice to the discussants-advice that they can follow and advice that has at least a chance of motivating them to mend their ways. I have tried to show that the consensus theory yields such advice and that the epistemological approach does not.

Third, it seems that one of the lessons that emerges from a consideration of argumentation theory is identical to a piece of folk wisdom: There is no point in arguing with some people. It seems like the right thing to say about crazy people, at least in ordinary contexts, is that it makes no sense to try to convince them of much of anything. That's what makes them crazy. Now, there may be other contexts (e.g., contexts where we know a person very well, contexts where a person's view runs counter to her own observations, etc.) in which we can get through to crazy people. If we think we can show them, using their own unarguedfor assumptions, that their view on some matter is mistaken, then it is worth a try. Otherwise, to debate a crazy person is a waste of time. (Consider whether you would even try to argue with someone who honestly believes that whoever yells loudest has the best argument.) But the rest of us can have all sorts of meaningful debates about issues that interest us. Furthermore, our debates can be meaningful and might lead to resolution, as long as we do not merely assume what our codiscussants deny.

\section{Conclusion}

I have tried to show the following in this paper: The normativity we should be concerned with, when it comes to argumentation, is the kind of normativity associated with giving advice. And if we are at all concerned to develop a theory of argumentation that results in useful, real-world advice, then the consensus theory looks more promising than the epistemological approach. Furthermore, when we pay attention to the right kind of normativity, the main criticism of the consensus theory fails. Since this criticism serves as the main rationale for adopting the epistemological approach, we lack good reason to accept the view. ${ }^{6}$

\section{Notes}

'It should be noted that there are some important differences between Biro and Siegel's view and Goldman's view. However, these differences are not relevant to the main topic of this paper.

${ }^{2}$ Because advocates of the epistemological approach do not present their view in terms of the advice it offers, my take on the advice it offers is, to some extent, an educated guess. If I have not characterized the advice correctly, then it is up to advocates of the epistemological approach to set the record straight and to do so in such a way that their view remains unique when compared to the consensus theory. Suffice it to say that given how the epistemological approach defines good argumentation, my characterization of the advice it offers is prima facie plausible.

${ }^{3}$ Ultra-deep disagreements are similar to the "deep disagreements" discussed by Robert Fogelin. (See Fogelin 1985.) 
${ }^{4}$ Note that dialethists are not purely fictional. The logician Graham Priest advocates dialethism. (See Priest 1988, 2001.) And if Richard Nisbett and his colleagues are correct, then East Asians, unlike Westerners, are inclined to think some contradictions are true. (See Peng \& Nisbett 1999, 2000 and Nisbett et al. 2001.)

"I do not mean to make light of mental illness in using the term "crazy." I use it not to refer to people with mental illnesses, but rather as a catch-all term to refer to those people who seem to us to have ludicrous opinions.

${ }^{6}$ I would like to thank Christoph Lumer and two anonymous reviewers for Informal Logic for helpful comments. Thanks too to Kristin Andrews and Michael Gilbert for feedback on an earlier draft.

\section{References}

Biro, J. and H. Siegel. 1992. "Normativity, Argumentation and an Epistemic Theory of Fallacies," in Argumentation Illuminated, van Eemeren, et. al. (eds.), 85-103.

Biro, J. and H. Siegel. 1997. "Epistemic Normativity, Argumentation and Fallacies," Argumentation 11, 277-292.

Eemeren F.H. van and R. Grootendrost. 1992. Argumentation, Communication and Fallacies: A Pragma-Dialectical Perspective, Hillsdale, NJ: Lawrence Erlbaum.

Eemeren F.H. van and R. Grootendorst. 2003a. "A Pragma-dialectical Procedure for a Critical Discussion," Argumentation 17, 365-386.

Eemeren F.H. van and Grootendorst, R.: 2003b. "The Development of the Pragmadialectical Approach to Argumentation," Argumentation 17 387-403.

Eemeren F.H. van, R. Grootendorst, J.A. Blair, C.A. Willard (eds.). 1992. Argumentation Illuminated, International Society for the Study of Argumentation, Amsterdam.

Fogelin, R. 1985. "The Logic of Deep Disagreements," Informal Logic 7, 1-8.

Goldman, A. 1999. Kriowledge in a Social World, Oxford: Oxford University Press, Chapter 5, 131-160.

Nisbett, R., K. Peng, I. Choi, A. Norenzayan, A. 2000. "Culture and Systems of Thought: Holistic v. Analytic Cognition," Psychological Review 108, 291-310.

Peng, K and R. Nisbett. 1999. "Culture, Dialectices, and Reasoning about Contradiction," American Psychologist 54, 741-754.

Peng, K and R. Nisbett. 2000. "Dialectical Responses to Questions About Dialectical Thinking," American Psychologist 55, 1067-1068.

Perelman, Ch. and L. Olbrechts-Tyteca. 1969. The New Rhetoric: A Treatise on Argumentation. Notre Dame: University of Notre Dame Press.

Priest, G. 1998. "To Be and Not to Be? That is the Answer: On Aristotle on the Law of Non-contradiction," Philosophiegeschichte und Logische Analyse, 1, 91-130.

Priest, G.. 2001. An Introduction to Non-classical Logic. Cambridge: Cambridge University Press.

Brian Huss

Philosophy Department

York University

4700 Keele Street

Toronto, ON M3J IP3

huss@yorku.ca 